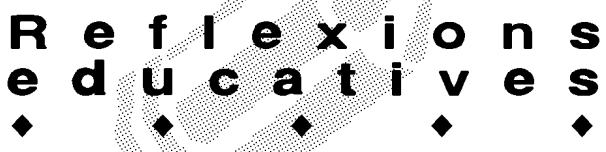

\section{EL MATERIAL REUTILITZAT A LES SESSIONS DE PSICOMOTRICITAT}

\author{
Isabel Viscarro Tomàs. Àrea de Didàctica de l'Expressió Corporal. URV. \\ Ma Dolors Comí Julià, M. Pilar Solé Andreu i Josepa Solsona Bes. Mestres d'Educació Infantil.
}

\section{Introducció}

Sovint es qüestiona la dificultat de fer sessions de psicomotricitat si no es disposa de força material i que, a més a més, sigui específic i variat.

El cert és que la realitat de les escoles és molt variada, des de les que disposen d'una bona dotació de material, que han anat aconseguint de mica en mica, fins a aquelles on la provisió és mínima. Tot i així, el fet de tenir pocs recursos materials no hauria de ser un impediment per treballar la psicomotricitat. Sovint el fet de tenir pocs recursos materials afavoreix la imaginació i la creativitat del mestre o de la mestra, per buscar alternatives perquè els infants puguin experimentar $\mathrm{i}$ viure amb plaer diferents situacions educatives amb el cos i a través del cos.

Els materials s'incorporen a les sessions com a mitjans i recursos per potenciar la vivència i l'experimentació dels nens i nenes; l'ús d'objectes i materials en aquestes sessions, com indica Defontaine (1982), afavoreix "un augment en l'activitat motriu, estimula les funcions cognitives i per l'afectivitat i les emocions en què l'infant investeix el material, els introdueix a la dimensió relacional infant-objecte-situació-l'altre".

Per aquest motiu, plantegem una proposta amb la intenció de donar algunes idees per treballar la psicomotricitat utilitzant material de reciclatge. Aquest material, que normalment es llença, està a l'abast de tothom, pot ser un recurs important que cal tenir present, especialment per a aquelles escoles que disposen de pocs materials convencionals per realitzar aquestes sessions. Amb això no volem dir que la proposta no la pugui tenir en compte tothom, ja que també, si es disposa de suficient material, introduir-ne de nous aporta noves idees i possibilitats, i desvetlla la imaginació i la creativitat dels infants.

\section{De quins materials parlem?}

- Capses de cartró de diferents grandàries, des de capsetes de formatget fins a caixes de neveres.

- Tubs de cartró dels rotllos de paper higiènic, d'alumini, de cuina.

- Materials d'embalatge i envasos: porexpan, plàstic de bombolles, bosses de plàstic de diferents mides, oueres, iogurt, tetrabrik.

- Papers de diari, de revista, d'embalar, higiènic, entre altres.

- Ampolles i garrafes de plàstic.

- Retalls de roba.

- Cordes, cordills i/o tires de llana, i tots aquells materials de desfeta que se us acudeixin.

Aquests materials es troben a l'entorn de l'infant, són coneguts, però possiblement no han tingut l'oportunitat de haver-los explorat i experimentat.

A més, aquest material és fàcil d'aconseguir i és econòmic. La mestra pot demanar als nens i nenes que facin una recollida de material a casa seva.

Es podria aprofitar per introduir el tema del reciclatge i la diferenciació de les deixalles. Això permet fer un treball interdisciplinari en les tres àrees d'Educació Infantil.

La utilització d'aquests recursos materials afavoreix en l'infant el joc sensòrio-motor i perceptiu-motor; el joc simbòlic; l'observació, manipulació, exploració i l'experimentació; el desenvolupament de la creativitat i la imaginació; les interaccions amb els altres; les activitats de reflexió-interiorització-representació (verbal o gràfica).

Objectius didàctics en relació amb aquests materials:

- Experimentar les sensacions que comporta el joc motriu.

- Explorar a nivell sensorial i perceptiu, mitjançant la manipulació.

- Conèixer les sensacions de les diverses parts del cos.

- Distingir diferents textures.

- Identificar-los i descobrir les seves característiques.

- Coordinar i controlar la força i la pinça en les accions d'encaixar, picar, rebregar, allisar, cargolar, embolicar, fer rodolar, tapar, apilar, foradar, transformar, lligar...

- Explorar les nocions espacials d'orientació, situació i direcció.

- Transformar-los mitjançant la manipulació. 


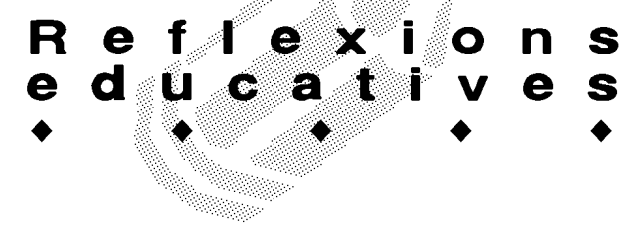

- Fomentar la creativitat mitjançant els diferents usos que l'infant pot donar-los.

- Agrupar els elements que tinguin la mateixa qualitat.

- Saber compartir el joc i el material.

- Fruir descobrint i inventant noves possibilitats d'ús, mitjançant el joc motriu, perceptiu i simbòlic.

- Potenciar la recollida selectiva de deixalles.

\section{Activitats d'ensenyament-aprenentatge}

Plantegem algunes de les activitats individuals o en grup, que es poden fer amb aquests materials, que poden estar distribuïts per racons o bé utilitzant tot l'espai, en funció de la proposta.

Paper de diari, de revista, d'embalar, higiènic, de precinte.

- Escampar a terra fulls de diari i revista en abundància.

- Desplaçar-se per sobre de diferents maneres: que corrin, saltin, llisquin, caiguin, es tirin sobre el paper; es tapin, es colguin sota el paper, i és possible que es produeixin processos d'excitació i de descàrrega d'energia.

- Amb un full de paper embolicar-se diferents parts del cos; esquinçar-lo; foradar-lo; esmicolar-lo; tirarlo enlaire; doblegar-lo de gran a petit; bufar-lo; inspirar fort per apropar-lo al nas; fer passeres $i$ camins.

- Transformar-lo en nous objectes: cucurutxo, boles, barret, capa, faldilla, ullera de llarga vista. I d'altres i fer-los servir per disfressar-se.

- Construir en petits grups i amb l'ajut de paper de precinte una pilota gran, un llençol... i crear jocs amb aquests elements construïts.

- Deixar en un racó altres tipus de paper: higiènic, d'embalar; per parelles embenar-se diferents parts del cos, mesurar la llargada del cos amb el paper i fer comparacions; estirats sobre un tros de paper d'embalar, fer-los resseguir la silueta del company amb un guix, retallar-la, posar-hi elements a la cara i decorar-la, reconèixer la seva i les dels companys/es.

- Experimentar amb les diferents textures dels papers.

Tubs de cartró dels rotllos de paper higiènic, d'alumini, de cuina,...), material d'embalatge (plàstic de bombolles, porexpan) i envasos (oueres, iogurt, tetrabrik...)

- Experimentar i manipular amb el material diferenciant les textures, formes i possibles usos.

- Fer sèries d'objectes atenent la seva dimensió, alçada, gruix, longitud.

- Fer construccions horitzontals i verticals.

- Transportar-los en equilibri sobre diferents parts del cos; sobre l'abdomen per seguir el moviment respiratori; jugar a fer lluites amb els tubs; tirar a l'aire; llançar i rebre els envasos de iogurt; fer conduccions amb un tub d'un altre objecte.

- Simbolitzar, donant-los diferents significats, etc.

Capses de cartró de diferents mides des de capsetes de formatget fins a caixes de neveres.

- Muntar circuits amb les caixes grans per poder entrar i sortir, desplaçar-se arrossegats, en quadrupèdia, asseguts per dins els passadissos creats amb les caixes.

- Experimentar la direcció i sentit.

- Construir, amb caixes i l'ajut de cordill, carretons que propiciïn accions d'arrossegar i empènyer.

- Amb capses que tinguin tapa, treure-les i fer aparellaments. Fer seriacions per mides. Fer apilaments.

- En grup de tres i una capsa, seguir els suggeriments de la mestra: segments concrets del cos dins de la capsa; els tres nens del grup dintre, tots fora, un dintre i dos fora... anar variant les consignes.

- Desplaçar-se amb una capsa a cada peu.

- Posar capses dins d'altres, de petita a gran.

- Fer punteria amb les boles de paper dins la caixa, des de diferents distàncies. Arrossegar un company ficat a la capsa.

Retalls de roba

- Experimentar amb diferents maneres de portar el tros de roba, de posar-se-la, i les diverses accions que s'hi poden fer: arrossegar, ser transportat amb diferents postures corporals, córrer i fer-les volar, espolsar-les, retorçar-les, Ilançarles i que caiguin a sobre.

- Embolicar un company i desembolicar-lo rodolant per terra, tapar-se diferents parts del cos, quedarse immòbils sota la roba. Disfressar-se.

Ampolles i garrafes de plàstic

- Construir camins per desplaçar-se de diferents maneres, experimentant línies rectes i corbes.

- Fer llançaments amb un objecte per tombar-les, jugant amb les distàncies.

- Col-locar-les a una certa distància per saltarles.

- Lligar les garrafes amb un cordill i arrossegarles de diferents maneres.

- Fer servir les ampolles per conduir un objecte.

\section{Continguts que es treballen}

Les propostes a partir d'aquest material ens permeten 


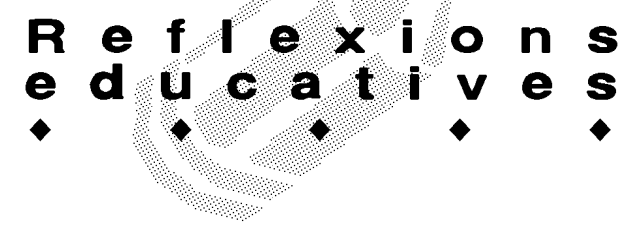

fer un treball interdisciplinari de les tres àrees d'educació infantil: descoberta d'un mateix, descoberta de l'entorn natural i social i intercomunicació i llenguatges.

Per això, els continguts esmentats a continuació fan referència a les tres àrees de coneixement, i també als tres tipus de continguts del currículum: procedimentals, conceptuals i actitudinals.

- Coneixement del propi cos i experimentació de les diferents sensacions, emocions $i$ interaccions que possibiliten els diferents materials.

- Manifestació a través de l'expressivitat motriu de les pròpies emocions, interessos i preferències.

- Control postural.

- Control i inhibició del moviment: mobilitat i immobilitat

- Organització de la lateralitat.

- Percepció i control respiratori.

- Manteniment de l'equilibri estàtic, dinàmic i dels objectes.

- Coordinació dinàmica general.

- Coordinació òculo-motriu.

- Motricitat fina.

- Regulació i control de ritmes.

- Reconstrucció, mitjançant el joc simbòlic, de situacions reals o de ficció.

- Descoberta de les qualitats físiques del material.

- Treball sensorial: vista, oïda i, especialment, tacte.

- Observació i exploració de les qualitats i propietats sensibles dels objectes a partir de la manipulació directa.

- Agrupacions i relacions qualitatives i quantitatives de similitud o de diferència dels materials de reciclatge utilitzats.

- Relacions espacials d'orientació, organització i direccionalitat: davant-darrere, a un costat-a l'altre, dalt-baix, a sobre-a sota, lluny-a prop, endavant-endarrere, cap amunt-cap avall.

- Experimentació i control dels desplaçaments dins i fora de les caixes.

- Experimentació de direcció i sentit.

- Experimentació de línies rectes i corbes.

- Reconeixement de formes geomètriques.

- Nocions bàsiques relacionades amb la geometria: dintre-fora, obert-tancat.

- Comparació de mesures d'aquests objectes: granpetit-mitjà, ample-estret, llarg-curt, gruixut-prim, alt-baix, pesant-lleuger.

- Relacions, correspondències i comparacions entre els objectes.

- Reconeixement i discriminació de textures: llis, rugós, aspre, suau.

- Transformacions dels diferents elements manipulables.
- Aplicació i utilització del vocabulari referit a les qualitats perceptives dels materials emprats.

- Reconeixement i discriminació de sons produïts amb els materials.

- La pròpia identitat i la relació amb els companys.

- Iniciativa i autonomia per resoldre les pròpies necessitats o per demanar ajut quan cal.

- Expressió verbal de les pròpies vivències i experiències.

- Representació de la vivència corporal a través de la verbalització, el dibuix, la construcció.

- Identificació dels materials de reciclatge emprats.

- Sensibilització cap al material de reciclatge.

- Formació d'hàbits ecològics.

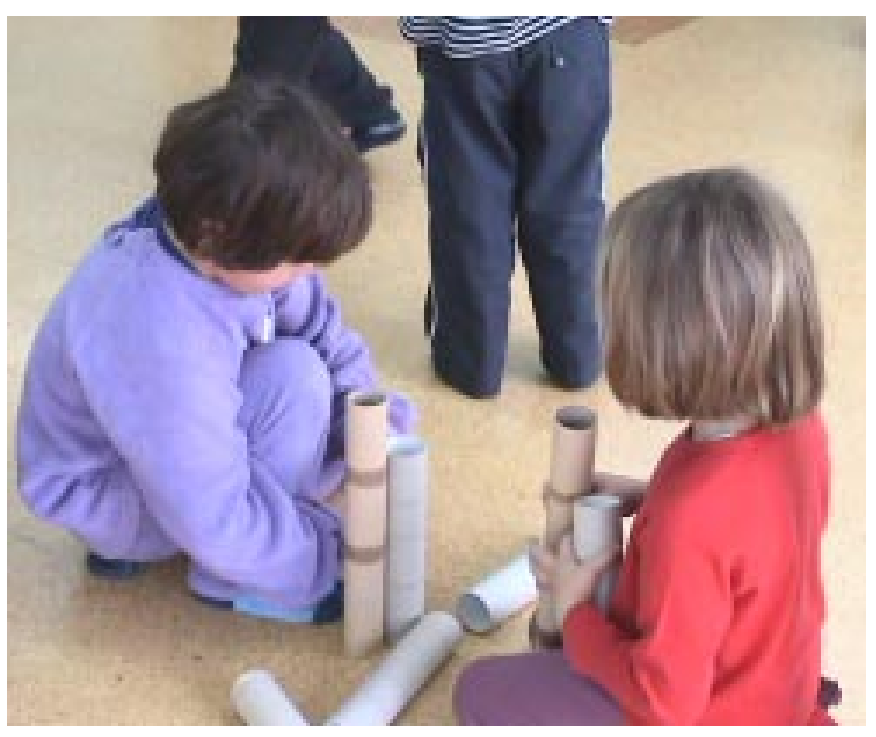

\section{Metodologia}

Aquesta proposta de treball té en compte els principis generals del disseny curricular per a l'etapa d'educació infantil. Aquests principis són: globalització, aprenentatge significatiu, individualització, metodologia activa i lúdica. Coincidim amb Justo (2000) quan indica que els mateixos principis són compartits per l'educació psicomotriu.

Globalitat i globalització de l'ensenyament

Destaca la importància de potenciar i afavorir totes les capacitats que integren la persona: cognitiva, afectiva, motriu i social. L'educació psicomotriu parteix d'aquesta globalitat de l'infant, tal com afirma Tejedor (2002): "aquesta pràctica ajuda els petits alumnes a formar-se globalment i equilibradament en els aspectes mentals, corporals i emocionals, sabent que això tan sols s'aconsegueix en una relació de seguretat afectiva".

Com heu pogut observar, tant les activitats proposades com els continguts posen de manifest aquesta 


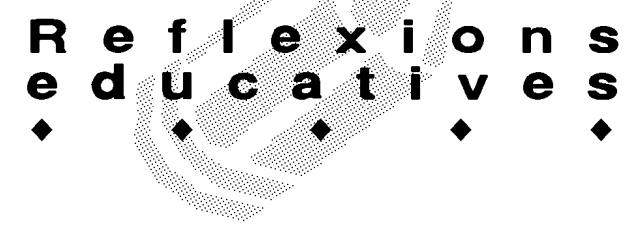

globalitat perquè tenen en compte tots els aspectes de l'infant, i també la globalització dels aprenentatges.

L'infant, mentre realitza aquestes activitats de manera lúdica, descobreix, pensa, aplica coneixements, experimenta, viu diverses situacions, s'emociona, es relaciona, resol conflictes, soluciona problemes...

Aprenentatge significatiu

Es fonamenta en el fet que tota intervenció educativa ha de procurar aprenentatges significatius. L'educació psicomotriu promou aquest tipus d'aprenentatge perquè és un procés actiu, dinàmic i ple d'interaccions de la realitat física i social. Les propostes presentades tenen en compte aquest principi perquè parteixen dels interessos, necessitats i motivacions dels infants, s'utilitzen uns materials amb gran potencial significatiu que els infants poden vivenciar, manipular, transformar i perquè afavoreixen situacions educatives que permeten integrar els aprenentatges nous amb els que l'infant ja té adquirits.

\section{Individualització}

Consisteix a adaptar les estratègies educatives a les característiques individuals de cadascú i respectar la diversitat. L'educació psicomotriu té en compte aquest principi, perquè parteix de les competències i de la valoració dels aspectes positius de cada infant, té en compte les seves limitacions ajudant-lo a superar-les, i respecta el ritme i el nivell d'aprenentatge de cadascú.

\section{Metodologia activa i lúdica}

El joc és l'activitat natural en els infants, té una gran importància educativa, és un instrument privilegiat d'aprenentatge, ja que permet a l'infant posar en pràctica totes les seves capacitats. Aquest serà constructiu en la mesura que l'infant vagi descobrint propietats i relacions a través de l'acció i l'experimentació. L'educació psicomotriu des d'un plantejament lúdic potencia l'experimentació de les vivències espontànies amb el propi cos, amb els altres, amb els objectes, amb l'espai i amb el temps.

Les activitats proposades respecten els interessos de l'infant i del grup, i afavoreixen la creativitat del nen i la nena a partir de l'activitat espontània i lúdica, respectant la seva expressivitat psicomotriu.
Pel que fa a la intervenció del mestre o de la mestra, a més a més de tenir en compte aquests principis, caldrà que organitzi l'espai, el temps, els materials, la manera de presentar-los i les propostes educatives per tal que permetin l'activitat motriu espontània i significativa dels infants, com a punt de partida de l'exploració, descobriment i coneixement de l'entorn.

El seu paper serà el d'acompanyar i motivar l'infant en el camí de l'experimentació, comunicació i creació.

Les consignes verbals haurien de ser, fonamentalment, obertes i flexibles per tal que donin Iloc a les màximes possibilitats de resposta. Les propostes i suggeriments que es facin han de possibilitar la creativitat... Les consignes tancades serien més apropiades per donar normes de funcionament i fixar límits seguritzants.

Aquesta flexibilitat permet tenir en compte la iniciativa dels infants, el seu desig, les seves competències..., afavorint el desenvolupament de l'autoestima i la valoració, l'acceptació i respecte a les descobertes i propostes dels altres, l'ajuda en un moment donat, la valoració, l'esforç i el foment de la iniciativa i la creativitat dels nens i nenes.

Aquestes activitats són flexibles, es poden dur a terme en qualsevol moment del curs i es poden adaptar a qualsevol nivell de parvulari.

\section{Bibliografia consultada}

DEFONTAINE, J. Manual de reeducación psicomotriz. Ed. Médica y Técnica. Barcelona. 1982.

GARCíA, E. i RUIZ, F. Educación Física a través del juego. Materiales no convencionales. Ed. Gymnos. Madrid. 2001.

GENERALITAT DE CATALUNYA. Curriculum d'Educació Infantil. Ed. Departament d'Ensenyament. Barcelona. 1992.

JUSTO, E. Desarrollo psicomotor en educación infantil. Bases para la intervención en psicomotricidad. Ed. Universidad de Almería. Almería. 2000.

TEJEDOR, P. La práctica psicomotriz educativa y la relación de identidad en educación, a "Aula de Innovació Educativa», 109 (2002) 18-20. Barcelona.

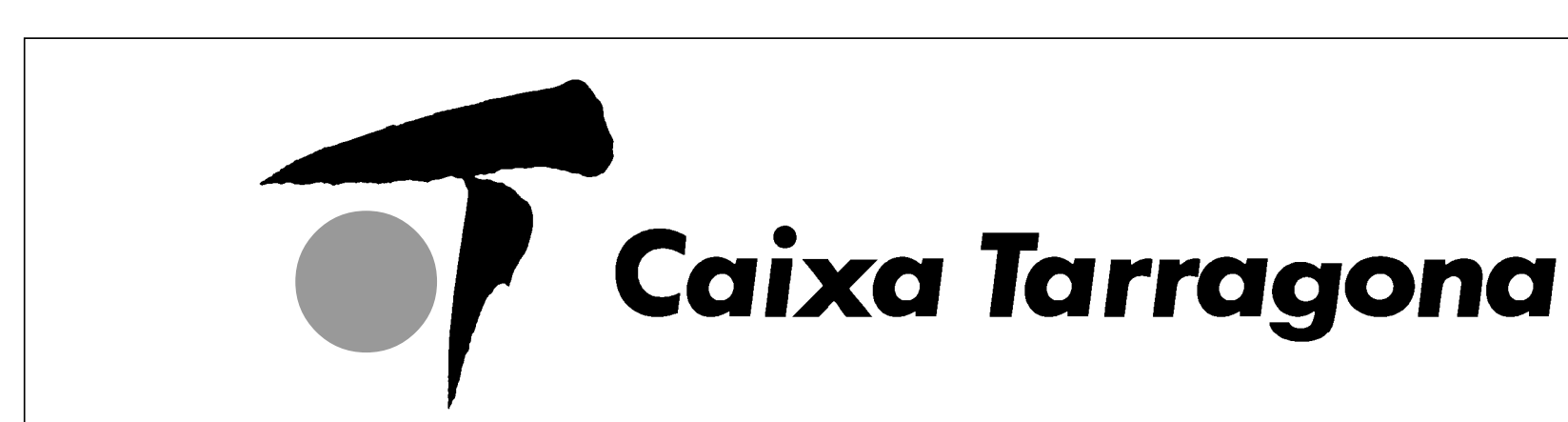

